\title{
Canadian Periodicals and Intellectual History: The Case of the McGill University Magazine/ University Magazine, I90I-I920
}

Peter F. McNally

OF ALL THE SUBDIVISIONS WITHIN BIBLIOGRAPHY, HISTORICAL BIBLIOgraphy remains the one with the greatest controversy surrounding its basic definition. Depending upon one's point of view, it can be defined narrowly as the history of the book or broadly as the study of books and other media as a mechanism for the transmission of culture and thought through time. Writing in 1967, Derek Williamson opted for a narrow definition and considered historical bibliography as a field which

... studies the historical development of books, the materials of which they were made, how these materials were manipulated and combined, and how the resultant objects were distributed. ${ }^{1}$

On the other hand, Roy Stokes, writing two years later, indicated the possibility of a much broader definition:

The final area to which attention is already beginning to be paid is that of the fringe area between historical bibliographical studies and history and literature in general. This can take a number of forms. One of the most significant is that which is entered upon following the completion of the processes of manufacture and distribution of the book. The book is essentially a reading tool and not an end product in itself. Consequently, although its history in a limited sense may be complete with its distribution its purpose has yet to be fulfilled. Any survey of reading tastes and influences is, therefore, of prime concern to the bibliographer as it is to the historian or the literary critic.... Here, historical bibliography probably reaches the point at which it arrives very close to the point where textual bibliography also stands. ${ }^{2}$

An important example, cited by Stokes to exemplify this definition, is Altick's The English Common Reader. ${ }^{3}$ Yet by extension, it would be easy to justify including within his definition historical studies which trace or evaluate ideas and opinions as they appear in books and other media. Of course, such studies should include an obvious bibliographic apparatus. Eisenstein's The Printing Press as an Agent of Change 4 and various studies of Diderot's Encyclopédie $e^{5}$ come immediately to mind as examples.

It is with this latter, broader definition of historical bibliography in mind 
that this paper has been written. To gain access to the contents of periodicals is not an end in itself. Rather this access is required in order first to ascertain specific reference information and second to gain an understanding of the general trend of thought and opinion which existed in a specific title or titles. The current indexing of periodicals is usually - and correctly - designed to facilitate the easy retrieval of specific information. By contrast, the retrospective indexing of periodicals, if done in aid of historical/intellectual bibliography, should aim to provide an understanding of the general shape or pattern of thought which characterized the publication.

Before amplifying upon these suggestions, some attention must first be paid to the state of Canadian intellectual history and to the state, past and present, of Canadian periodical publishing. Writing in 1977, Carl Berger said,

Social and intellectual history are not highly developed aspects of Canadian historical writing and any description of the works in these areas must necessarily be rather fragmentary. ${ }^{6}$

Yet in the remaining sixteen pages of his very informative but selective bibliographical essay, he reveals how much work has been done in these fields in recent years, along with an indication of how much still needs doing. Furthermore, studies by Berger ${ }^{7}$ himself, Shortt ${ }^{8}$, and McKillop ${ }^{9}$ all reveal the vitality behind recent research and writing on Canadian intellectual history. With their elaborate bibliographical apparatuses, the studies of these three men substantiate the contention that only through sure-footed bibliographical work can intellectual historians discover and document the origin and movement of thought and opinion, popular and otherwise, through time and various media.

As for Canadian bibliographers contributing to historical/intellectual bibliography, few examples can be found. To enumerate, in various forms, has been the function of most of our bibliographers - very worthwhile and necessary in a relatively young country. Tremaine's Bibliography of Canadian Imprints ${ }^{10}$ through its strength of concept, its exhaustivity, its organization, its annotations, and its excellent introduction is the best example we have at present. It presents - both implicitly and explicitly - an appreciation of Canadian thought and opinion in the last half of the eighteenth century, as conveyed through books and other printed materials, which has yet to be surpassed.

Concerning the state of Canadian periodical publishing, the hesitant and slow growth which characterizes most aspects of Canadian culture is also to be found here. Since the Nova Scotia Magazine ${ }^{11}$ (I789-I792), the first, appeared almost two hundred years ago, there have been thousands of Canadian titles. W.H. Kesterton speaks of their extremely high mortality rate. ${ }^{12}$ Only the Queen's Quarterly (I893-) and Saturday Night (I887-) come readily 
to mind as continuing titles which began in the nineteenth century. Economically and editorially viable periodicals have never been plentiful in Canada. Their quality has covered the usual range from very good to very bad with every shade in between. Even so, Emilio Goggio was able to list approximately four hundred titles in his 1955 list of Canadian cultural periodicals. ${ }^{13}$

A number of reasons can be presented for studying Canadian periodicals. They perform the same three services which Frank Mott ascribed to American periodicals:

First, they provide a democratic literature which is sometimes of high quality ... They have printed some literature of excellent quality... Second, the magazine has played an important part in the economics of literature ... [They] have unquestionably done much to stimulate the book trade by inculcating reading habits, by the discussion of books in their pages, and by familiarizing their readers with literary reputations ... Third, periodical files furnish an invaluable contemporaneous history of their times ... Few fields of investigation are of more lively interest than that of the course of popular ideas ... Where is there such a record of these things as we have in the magazine files? ${ }^{14}$

This third reason is particularly important for the historical/intellectual bibliographer. As the footnotes and bibliographies of the previously mentioned works by Berger, Shortt, and McKillop ${ }^{15}$ have shown, Canadian periodicals are a rich - and largely untapped - source of contemporary information concerning Canadian thought and opinion. The question for the beginning historical bibliographer is how to go about investigating a Canadian periodical as a vehicle for the transmission of thought and ideas.

The remainder of this paper will be a case study of three separate attempts which have been made to analyze one Canadian periodical, which began life in I90I as the semi-annual McGill University Magazine (Vol. I-5, I90I-I906) and changed its name to the University Magazine (Vol. 6-19, 1907-1920) when it became a quarterly. Of the three studies two were master's research papers in Canadian History and one a master's thesis in English Literature. They will be evaluated in the light of a broad definition of historical/intellectual history: how well they balanced the dual requirements of providing bibliographical access to the Magazine (indexing) and of analyzing and evaluating its contents.

In the early years of this century, McGill University and the University of Toronto were generally considered to be Canada's leading universities. ${ }^{16}$ Commentators might disagree on which came first, but not on their dual supremacy. To the extent that McGill possessed an advantage, it was in being a private institution which received little money and fewer directions from government. Wealthy benefactors like Sir William Macdonald and Lord Strathcona permitted the McGill of the turn of the century to become one of 
the continent's leading centres for the study of science and medicine. Between I895 and I9I9 the endowment rose from $\$ 1,500,000$ to $\$ 12,000,000$ and annual income from $\$ 200,000$ to $\$ 1,000,000$, both well ahead of the then rate of inflation.

During the same period, academic vitality was displayed in the development of professional schools in music, social service, dentistry, physical education, and graduate studies. Another aspect of this academic vitality occurred with the appearance in r9or of the McGill University Magazine. Its three aims were: to publish the serious, non-technical, non-theological writings of members of the University; to provide a gazette and forum in which University activities could be publicized and debated; and to maintain contact with McGill graduates. ${ }^{17}$

A McGill Board of Governors' minute of 1906 indicated that although it was not an official publication, it did possess the University's official approval. ${ }^{18}$ These facts have led Shortt, along with others, to dismiss it as 'pallid' and little more than an 'alumnae' magazine. ${ }^{19}$ On the other hand, McNally disputed this interpretation, while admitting the preponderance of McGill topics and contributors. ${ }^{20}$ The McGill University Magazine under the editorship of Charles E. Moyse, he argued, made a sufficient contribution to be considered one of the leading Canadian journals of culture and general intellectual interest. Certainly the contribution was sufficient - in terms of contents, circulation and advertising - that when reorganized with Volume 6 (1907) under the editorship of Andrew Macphail, it achieved both contemporary and historical praise. From then until its demise in 1920, the Magazine was in theory run jointly by McGill, Dalhousie, and Toronto Universities, through an editorial committee. In fact, McGill, through the editor Macphail, maintained firm control over it. Berger has written that as the University Magazine, it was

one of the finest periodicals of political and literary comment to appear in English Canada between the expiry of the Week in 1896 and the appearance of the Canadian Forum in $1920 .{ }^{21}$

What sort of magazine was the McGill University Magazine/University Magazine that it should have elicited so much favourable response? Aside from the stray and pragmatic elements which enter into all general periodicals and aside from the McGill topics in the first five volumes, certain basic themes remained constant throughout its twenty-year history. First, it never wavered from its belief and support of imperialism, that multi-faceted ideology of early twentieth-century Canada. ${ }^{22}$ Second, it espoused a conservative view of society which emphasized moral and social values. ${ }^{23}$ Third, to the extent that it espoused social reform, it did so in the light of philosophical idealism; it 
attempted to give voice to a social ethic that reconciled traditional religious and humanistic values with science, material improvement, and social change. ${ }^{24}$

Fourth, it published important Canadian poetry and short stories. ${ }^{25}$ World War I shattered its ideologies, its circulation, and its editor's enthusiasm. ${ }^{26}$ In I920 it ceased publication. The Dalhousie Review (I920- ), the Canadian Forum (I920- ), and the University of Toronto Quarterly (I93 I- ) were to fill the void only partially.

Considerations of the three studies - or biographies - of the McGill University Magazine/University Magazine will be chronological by period covered. As an aside, it should be pointed out that these three concentrated exclusively on the Magazine, whereas previously mentioned studies by Berger, Shortt, McKillop, ${ }^{27}$ and others have investigated it only in the course of studying other topics like imperialism and idealism. Both approaches are equally important and equally valid. For the purpose of this paper, however, concentration is placed upon historical/intellectual bibliography in relation to the study of a specific periodical title.

The first study, chronologically, is Peter F. McNally's 'The McGill University Magazine, I90I-I906: An Evaluation and a Bio-bibliographical Analysis'.28 As the title suggests, it made a self-conscious attempt to provide both access and analysis of the contents only of the McGill University Magazine, Volumes I to 5 . The bio-bibliographical analysis provided the key to the evaluation of the contents. This was done first by providing a 'Biographical Index'29 with brief sketches of seventy of the seventy-three identifiable contributors to the Magazine, which in turn permitted a profile to be made of them in general and in relation to specific topics. Secondly, there were prepared author ${ }^{30}$ and subject ${ }^{31}$ indexes of the Magazine's articles. Because it did not adhere to Harold Borko's dictum of 'maximum specificity', ${ }^{32}$ the subject index presented one of this study's more controversial elements. Rather, eleven broad headings were used which constituted in fact a classified organization (albeit arranged alphabetically) of the Magazine's I88 articles, poems, and short stories: current topics, editorials, education, history/biography, literary criticism, McGill University, McGill University-biography, miscellaneous, philosophy/science/technology, poems and short stories, travel and adventure. The obvious disadvantage of such an approach was that it prevented easy reference access to articles on specific topics. The obvious advantage was that it permitted the author to gain insight into the Magazine's general trend of thought and opinion. Of the eleven broad topics, only the contents of the four most important were chosen for analysis: current topics, education, McGill University, and philosophy/science/technology. The headings used in this classified approach were not pre-ordained by any previously produced schematization. Rather, they emerged only after considerable 
thought and study of the articles themselves. Concerning the analysis of contents, suffice to say that a wide range of Canadian, American, British, and European sources was consulted as aids in evaluating various articles and in placing their ideas within appropriate intellectual contexts. The one aspect of analysis where bibliographical skills emerged strongly was in the introduction when considering elements such as advertisements, circulation figures, cover design, size, and frequency of issues.

The second study is Samuel E.D. Shortt's 'The Progressive Mind in Academic Canada: The University Magazine, I907-I9I4 ${ }^{\prime} \cdot{ }^{33}$ The most curious aspect of this work, bibliographically, was the impression given by the author that the Magazine ceased publication in I9I4, not in I92O as it did. Beyond that, he did provide a certain amount of bio-bibliographical information, but in a highly selective manner. First, he named the Magazine's twelve most frequent contributors along with the number of articles each had contributed during the years in question. ${ }^{34}$ For nine of them he provided brief biographical sketches which gave their birth-place, birth and death dates, age in I907, education, occupation, publications, residence, clubs, and pertinent miscellaneous facts. ${ }^{35}$ Some of this information was reflected in the body of the study. Shortt also listed the major articles from the 1907-I9I4 period in his bibliography. ${ }^{36}$ 'Only articles of absolutely no relevance, usually those concerned with esoteric, academic matters, are not included in the calculations ${ }^{\prime}{ }^{37}$ he said. He also listed the thirteen 'most frequent topics' ${ }^{38}$ for articles from this period, along with the number of articles on each. This can be seen, however, only as an embryonic attempt to provide a classed approach, since the articles themselves were not listed under these headings, nor was there any obvious correlation between the chapter headings and these topic headings. Concerning his analysis of the Magazine, Shortt interpreted it in the light of American progressivism. Interestingly enough, in his later work The Search for an Ideal, ${ }^{39}$ he interpreted the Magazine in the light of English idealism. The bio-bibliographical apparatus he employed in 'The Progressive Mind' indicated that he was on the correct path toward historical/intellectual bibliography. Lacking, perhaps, was the background or training to complete this approach.

The third study is by Kim Jones, 'A Content Guide and Index to the University Magazine'.40 Except for its five-page introduction, no attempt was made to analyze the Magazine's contents. Rather the entire emphasis of the thesis was placed upon bibliographic access: a 'Content Guide', ${ }^{41}$ which provided indicative abstracts of the Magazine's articles, poems, and short stories, plus author, ${ }^{42}$ title $^{43}$ and subject ${ }^{44}$ indexes of the articles. Despite this exclusive concentration upon bibliographical access, no mention was made of the study's most curious bibliographical aspect: why were only the years I9I0-I920 (Volumes 9-I9) covered and not the earlier ones. Concerning the 
subject index, broad not specific headings were used, which again suggested a classified approach. For instance, forty-three items were listed under the heading 'Theology and Religion', which had no subdivisions. The entire thesis possessed only two bibliographic citations, one to the Dictionary of National Biography ${ }^{45}$ and the other to the University Magazine ${ }^{46}$ itself. Both appeared in the introduction.

A recapitulation of these three studies of the McGill University Magazine/University Magazine, Volumes I-I9 (I90I-I920), is probably in order. Bibliographical control of varying quality was provided by all three. McNally (I90I-I906) and Jones (I9IO-I920) provided the best. McNally's approach emphasized an appreciation of the Magazine's general trend of thought and opinion through the classified approach, whereas Jones emphasized reference access, despite relatively broad subject headings, particularly through the title index and 'Content Guide'. Shortt (1907-I9I4) did provide some bibliographic access, but it was highly selective and designed primarily to meet the specific needs of his own project. Biographical access was provided most effectively by McNally (I90I-I906), who attempted to identify all of his contributors. Shortt (1907-I914) was again highly selective and identified only his nine most significant contributors. Jones (I9IO-I920) provided no biographical apparatus, except to identify the editor, Andrew Macphail, in the introduction. Concerning the analysis of contents, Jones (I9IO-I92O) provided none aside from the abstracts in the 'Content Guide', which were not footnoted and not developed in the light of any philosophical or ideological point of view. McNally (I90I-I906) and Shortt (I907-1914) placed great emphasis upon analysis. McNally was selective and evaluated only what he considered to be major topics but did so in the light of a wide range of turn-of-the-century ideas. Shortt also evaluated a selective range of topics but did so in the light of American progressivism. The most curious element of these three studies was why Shortt (I907-I9I4) and Jones (I910-I920) limited themselves only to their particular years. McNally (I90I-I906) made it clear that he was limiting himself to the McGill University Magazine (Volumes I-5). It seems strange that none of them should have attempted a study of the entire Magazine using the techniques of historical/intellectual bibliography.

This, of course, begs the question, what are the tenets of historical bibliography when applied to the study of a periodical and its ideas? There are basically three elements: bibliographical, biographical, and evaluative. The bibliographical has two separate sub-elements: macro and micro. The macro-bibliographical involves the correct identification of the title; its place and dates of publication; its changes of title; its editors, publishers, and printers. Also to be considered are its stated editorial purposes, its price, type-face, graphic design, circulation, and advertisements among other possible things. At the micro-bibliographical level, access must be provided to the contents of 
the periodical. This access should be exhaustive and not selective. An author/main entry index is a first priority. Attempts should be made to identify anonymous or pseudonymous work. Next the articles should be arranged in classified order, the classification tailor-made to the requirements of the articles. This classed approach is designed to provide an understanding of the periodical's general trend of thought and opinion. Or to put it another way, it organizes the knowledge in the title. Then as an optional element, a subject index might be provided for reference access, designed according to the rules of maximum specificity. Again, these headings might have to be tailor-made in whole or in part. A title index, except for poems and short stories, is probably unnecessary. Abstracts of the articles should be included only if time and resources permit.

Biographical access is the second required element in such a study. Every attempt must be made to identify all the contributors to the title or to that period of it being studied. A biographical dictionary or index should be compiled in which each individual is treated as consistently as possible. Information which should probably be included in each entry is: full name, birth and death dates, place of birth and death, education, work experience, and publications. Depending upon circumstances, modifications of this format may be made. All information should be presented in point form and should be footnoted. The resulting biographical dictionary will permit an analysis to be made of the contributors in general and in relation to various topics or even to specific articles.

The third element, analysis of the articles, will proceed in large part from the preliminary bio-bibliographical information which has been compiled. The macro-bibliographical information will provide much of the background or introductory information. The classified index to the articles will provide a ready-made table of contents to the various chapters. Of course, not all the topics or even all the articles within them will necessarily be analyzed. For those topics and articles which are analyzed, evaluation will occur in the light of a wide range of primary and secondary sources (mostly Canadian, American, British, French, and European) which discuss thought and opinion. This analysis will be designed to show the periodical's range and trend of thought. It will also show the extent to which its thought agreed with or varied from that generally held at the time.

Bonne chance!

NOTES

I. Derek Williamson, Historical Bibliography (Hamden, Conn.: Archon, 1967), p. Io9.

2. Roy Stokes, The Function of Bibliography (London: Deutsch, 1969), pp. 168-169.

3. R.D. Altick, The English Common Reader: A Social History of the Mass Reading Public, 1800-1900 (Chicago: University of Chicago Press, 1957). 
4. Elizabeth Eisenstein, The Printing Press as an Agent of Change: Communications and Cultural Transformations in Early Modern Europe (N.Y.: Cambridge University Press, 1979), 2 vols.

5. Robert Darnton, The Business of Enlightenment: A Publishing History of the Encyclopédie, 1775-1800 (Cambridge, Mass.: Belknap Press, 1979) and John Lough, The Encyclopédie (London: Longmans, 1971) are two good and complementary examples.

6. Carl Berger, 'Social and Intellectual History', in J.L. Granatstein, Canada Since 1867: A Bibliographic Guide (Toronto: Hakkert, 1977), p. 85.

7. Carl Berger, The Sense of Power: Studies in the Ideas of Canadian Imperialism, 1862-1914 (Toronto: University of Toronto Press, 1970).

8. Samuel E.D. Shortt, The Search for an Ideal: Six Canadian Intellectuals and Their Convictions in an Age of Transition, 1890-1930 (Toronto: University of Toronto Press, I976).

9. A.B. McKillop, A Disciplined Intelligence: Critical Inquiry and Canadian Thought in the Victorian Era (Montreal: McGill-Queen's Press, 1979).

Io. Marie Tremaine, A Bibliography of Canadian Imprints, 1751-1800 (Toronto: University of Toronto Press, 1952).

II. Ibid., pp. 653-656.

12. W.H. Kesterton, A History of Journalism in Canada (Toronto: McClelland and Stewart, 1967), pp. 25-26, 62-63, 170-175.

13. Emilio Goggio, A Bibliography of Canadian Cultural Periodicals (English and French from Colonial Times to 1950) in Canadian Libraries (Toronto: University of Toronto, Department of Italian, Spanish and Portuguese, 1955).

I4. Frank Luther Mott, $A$ History of American Magazines (Cambridge, Mass.: Harvard University Press, 1930), vol. I, pp. 2-4.

15. See notes $7,8,9$.

I6. Peter F. McNally, 'The McGill University Magazine, 190ı-I906: An Evaluation and a Bio-bibliographical Analysis' (Master's Research Paper, McGill University, 1976), pp. 14-17.

I7. Ibid., pp. 3-4.

I8. Ibid., p. 3 .

I9. Shortt, The Search for an Ideal, p. I6.

20. McNally, pp. I3-r4.

21. Berger, The Sense of Power, p. 47.

22. Shortt, The Search for an Ideal, p. 35.

23. Ibid., p. 34; Berger, The Sense of Power, p. I95.

24. McKillop, p. 23I.

25. Shortt, The Search for an Ideal, p. I8.

26. Ibid., pp. 17-I8.

27. See notes $7,8,9$.

28. For full information see note 16 .

29. McNally, pp. I48-I 57.

30. Ibid., pp. 122-133.

3I. Ibid., pp. I34-I47.

32. Harold Borko and Charles L. Bernier, Indexing Concepts and Methods (N.Y.: Academic Press, 1978), p. 60.

33. Samuel E.D. Shortt, 'The Progressive Mind in Academic Canada: The University Magazine, I907-1914' (Master's Research Paper, Carleton University, 1969). 
34. Ibid., p. i.

35. Ibid., pp. iii-v.

36. Ibid., pp. ix-xi.

37. Ibid., p. i.

38. Ibid., pp. i-ii.

39. Shortt, The Search for an Ideal, pp. 13-38.

40. Kim Jones, 'A Content Guide and Index to The University Magazine, Vols. IX-XIX, I910-I920' (Master's Thesis, Queen's University, 1954).

4I. Ibid., pp. I-I8O.

42. Ibid., pp. I8I-203.

43. Ibid., pp. 238-257.

44. Ibid., pp. 204-237.

45. Ibid., p. v.

46. Ibid. 